\title{
Follow-up after radiological intervention in oncology: ECIO-ESOI evidence and consensus-based recommendations for clinical practice
}

\author{
Monique Maas ${ }^{1} \mathbb{D}$, Regina Beets-Tan ${ }^{1}$, Jean-Yves Gaubert ${ }^{2,3}$, Fernando Gomez Munoz ${ }^{1,4}$, Paul Habert ${ }^{2,3}$, \\ Lisa G. Klompenhouwer ${ }^{1}$, Paulo Vilares Morgado ${ }^{5}$, Niklaus Schaefer ${ }^{6}$, Francois H. Cornelis ${ }^{7}$, Stephen B. Solomon ${ }^{7}$, \\ Denise van der Reijd ${ }^{1}$ and Jose Ignacio Bilbao ${ }^{8^{*}}$
}

\begin{abstract}
Interventional radiology plays an important and increasing role in cancer treatment. Follow-up is important to be able to assess treatment success and detect locoregional and distant recurrence and recommendations for follow-up are needed. At ECIO 2018, a joint ECIO-ESOI session was organized to establish follow-up recommendations for oncologic intervention in liver, renal, and lung cancer. Treatments included thermal ablation, TACE, and TARE. In total five topics were evaluated: ablation in colorectal liver metastases (CRLM), TARE in CRLM, TACE and TARE in HCC, ablation in renal cancer, and ablation in lung cancer. Evaluated modalities were FDG-PET-CT, CT, MRI, and (contrast-enhanced) ultrasound. Prior to the session, five experts were selected and performed a systematic review and presented statements, which were voted on in a telephone conference prior to the meeting by all panelists. These statements were presented and discussed at the ECIO-ESOI session at ECIO 2018. This paper presents the recommendations that followed from these initiatives. Based on expert opinions and the available evidence, follow-up schedules were proposed for liver cancer, renal cancer, and lung cancer. FDG-PET-CT, CT, and MRI are the recommended modalities, but one should beware of false-positive signs of residual tumor or recurrence due to inflammation early after the intervention. There is a need for prospective preferably multicenter studies to validate new techniques and new response criteria. This paper presents recommendations that can be used in clinical practice to perform the follow-up of patients with liver, lung, and renal cancer who were treated with interventional locoregional therapies.
\end{abstract}

Keywords: Recommendations, Interventional radiology, Oncology, Liver, Lung cancer

\section{Key points}

- Standardized follow-up after an oncologic intervention is needed to improve the quality of care.

- MRI, CT, and PET-CT are the main modalities.

- PET-CT is most valuable in lung cancer and colorectal liver metastases.

\footnotetext{
* Correspondence: jibilbao@unav.es

${ }^{8}$ Dept of Radiology, University Clinic of Navarra, Calle Benjamín de Tudela, 2, 31008 Pamplona, Navarra, Spain

Full list of author information is available at the end of the article
}

- RECIST 1.1 is suboptimal for follow-up after oncologic intervention.

- Research on adequate response evaluation methods is needed.

\section{Background \\ Interventional radiology plays an increasingly important role in the treatment of cancer. Interventional radio- logical treatments are mostly applied in liver, lung, and renal cancer. The main aims of follow-up after oncologic intervention are [1] early detection of residual tumor, [2]}

\section{Springer Open}

(c) The Author(s). 2020 Open Access This article is licensed under a Creative Commons Attribution 4.0 International License, which permits use, sharing, adaptation, distribution and reproduction in any medium or format, as long as you give appropriate credit to the original author(s) and the source, provide a link to the Creative Commons licence, and indicate if changes were made. The images or other third party material in this article are included in the article's Creative Commons licence, unless indicated otherwise in a credit line to the material. If material is not included in the article's Creative Commons licence and your intended use is not permitted by statutory regulation or exceeds the permitted use, you will need to obtain permission directly from the copyright holder. To view a copy of this licence, visit http://creativecommons.org/licenses/by/4.0/. 
detection of local tumor progression, and [3] detection of new lesions inside the target organ or distant metastases. Another important aim is to identify complications of the intervention. In general, response to local treatment is regarded as a surrogate endpoint for long-term outcome. Currently, no evidence and/or expert-based guidelines (regarding imaging modalities and follow-up schedule) exist for follow-up after several types of radiological intervention in oncology. Therefore, in current clinical practice, follow-up is heterogeneous and consensus on the most suitable follow-up modality and schedule is lacking.

A joint session from ECIO European Conference on Interventional Oncology (ECIO) and ESOI (European Society of Oncologic Imaging), which could be attended by visitors of the conference, was held in April 2018 with expert panelists and members of the ECIO and ESOI. The aim of this session was to construct recommendations on follow-up after specific radiological locoregional interventions: ablation in CRLM, TARE in liver cancer (hepatocellular carcinoma (HCC) and colorectal liver metastases (CRLM), TACE for HCC, ablation in renal cancer, and ablation in lung cancer (primary tumors and metastases). These recommendations were based on literature and expert opinion, which were discussed among a panel of experts in both diagnostics (ESOI) and interventional oncological radiology (ECIO).

This paper reports the recommendations that follow from this joint ECIO-ESOI session and provides a guide to use in clinical practice when dealing with follow-up after locoregional interventional treatment of liver, lung, and renal cancer.

\section{Methods}

Before the ECIO conference, experts per topic (total panelists: 5) were identified and asked to participate in the ECIO session as a panelist. A telephone conference was used to discuss the aims of the session and to start the construction of the recommendations. All participants were asked to provide a systematic review on their topic, according to the PRISMA guidelines for systematic reviews [1] for which a template was provided to the participants. The systematic review the panelists provided was a manuscript including the search question, search strategy (including in/exclusion criteria, number of hits, databases used), selection strategy of the identified papers, list of references), and a summary and discussion of the results from the included papers. Expert panelists were allowed to invoke assistance from colleagues for this systematic review.

The following topics were addressed:

1. Follow-up after radiological intervention for colorectal liver metastases, comprising of radiofrequency ablation (RFA), microwave ablation (MWA) (M.M., diagnostic radiologist).

2. Follow-up after transarterial radioembolization (TARE) for CRLM (N.S., diagnostic radiologist).

3. Follow-up after radiological intervention for hepatocellular carcinoma (HCC) by transarterial chemoembolization and TARE (P.V.M. and N.S., interventional radiologist and diagnostic radiologist).

4. Follow-up after radiological intervention for renal cell carcinoma (RCC) by RFA or MWA (S.S., interventional radiologist).

5. Follow-up after radiological intervention for primary lung cancer and lung metastases by RFA, MWA, and cryoablation (J.G., interventional radiologist).

The purpose of the search for all topics was the evaluation of accuracy or efficacy of imaging modalities to detect local tumor persistence, progression, or tumor recurrence. General exclusion criteria were [1] case reports, [2] meta-analysis, [3] reviews, [4] other locoregional therapies than specified above, [5] other language than English, and [6] mixed cohort studies where data on specific disease separately was not derivable. During the search, initially, intrahepatic cholangiocarcinoma was included but was later excluded given the lack of evidence on this topic. The details on the search question and strategy per topic are specified in Table 1.

After receipt of all the systematic reviews a second telephone conference was held to establish consensus on the conclusions and to summarize statements and recommendations derived from the systematic reviews as a basis for the session at ECIO 2018. All panelists approved the final statements and recommendations for each topic. The telephone conferences and establishment of consensus were moderated by R.B.T., J.I.B., and M.M..

The statements were sent to all panelists and they were asked to vote. All statements on which $\geq 80 \%$ agreement was reached were accepted as recommendations. All statements with $<80 \%$ consensus were discussed in a telephone conference and statements were deleted or adapted to achieve $\geq 80 \%$ consensus.

The result of the systematic reviews and telephone conferences with the experts are the bases of the currently presented recommendations. Final recommendations were based on a combination of systematic reviews, consensus meetings, and expert opinions. In case of limited evidence, expert opinion was the basis for recommendations.

\section{Results}

For follow-up after the oncologic intervention, the preferred modalities were found to be: CT, PET-CT, and 
Table 1 Search details

\begin{tabular}{|c|c|c|c|c|c|}
\hline Topic & Disease & Intervention & Modalities & Hits & Articles included \\
\hline Thermal ablation in CRLM & Colorectal liver metastasis & $\begin{array}{l}\text { Thermal ablation techniques: } \\
\text { radiofrequency, microwave }\end{array}$ & $\begin{array}{l}\text { CT, MRI, FDG-PET(-CT), } \\
\text { CE-US }\end{array}$ & 497 & 14 \\
\hline TARE in liver cancer & $\begin{array}{l}\text { Liver metastasis, intrahepatic } \\
\text { cholangiocarcinoma, } \\
\text { hepatocellular carcinoma }\end{array}$ & $\begin{array}{l}\text { Transarterial radioembolisation } \\
\text { (Yttrium90/TARE/SIRT) }\end{array}$ & $\begin{array}{l}\text { CT, MRI, FDG-PET(-CT), } \\
\text { Y } 90 \text { SPECT/CT/PET }\end{array}$ & 128 & 12 \\
\hline TACE in HCC & Hepatocellular carcinoma & Transarterial chemoembolization & $\begin{array}{l}\text { CT, MRI, FDG-PET(-CT), } \\
\text { CE-US }\end{array}$ & 417 & 69 \\
\hline Thermal ablation in RCC & Renal cell carcinoma & $\begin{array}{l}\text { Thermal ablation techniques: } \\
\text { cryoablation, radiofrequency, } \\
\text { microwave }\end{array}$ & $\mathrm{CT}, \mathrm{MRI}$ & 518 & 39 \\
\hline Thermal ablation in NSCLC & Non-small cell lung cancer & $\begin{array}{l}\text { Thermal ablation techniques: } \\
\text { radiofrequency, microwave }\end{array}$ & $C T, M R I$, FDG-PET(-CT) & 181 & 21 \\
\hline Exclusion criteria all topics & \multicolumn{5}{|c|}{$\begin{array}{l}\text { Case reports, meta-analysis, reviews, } \\
\text { other locoregional therapies, other } \\
\text { language than English, mixed cohort } \\
\text { studies where data on specific disease } \\
\text { separately was not derivable. }\end{array}$} \\
\hline Purpose in all topics & \multicolumn{5}{|c|}{$\begin{array}{l}\text { Evaluation of accuracy or efficacy of } \\
\text { imaging modalities to detect local } \\
\text { tumor progression or tumor } \\
\text { recurrence. }\end{array}$} \\
\hline
\end{tabular}

Abbreviations: CRLM colorectal liver metastases, HCC hepatocellular carcinoma, RCC renal cell carcinoma, NSCLC non-small cell lung cancer, CT computed tomography, MRI magnetic resonance imaging, FDG-PET fluorodeoxyglucose positron emission tomography, CE-US contrast-enhanced ultrasound, SPECT singlephoton emission computed tomography, TARE transarterial radioembolization, SIRT selective internal radiation therapy, TACE transarterial chemoembolization, Y90 Yttrium90

MRI. In some cases, ultrasound (sometimes contrastenhanced) is also an option. Proposed follow-up schedules and imaging protocols (for liver, kidney, and lung) are presented in Table 2. The results per topic are presented below. Table 3 presents the imaging features per topic that have been identified to indicate local tumor progression (LTP). The statements that were voted and the items that were discussed after voting are provided in supplementary material S1. Also, in the supplementary material, the consensus statements and recommendations per topic can be found (S2).

\section{A. Liver cancer: thermal ablation of CRLM, TARE of CRLM, and intra-arterial therapy (TACE and TARE) of HCC}

1. Follow-up after thermal ablation for colorectal liver metastases: RFA and MWA

Thermal ablation for colorectal liver metastasis is a potential curative option in patients who are not eligible for curative resection. Overall, survival is similar to resection, as long as maximally 5 lesions up to $3 \mathrm{~cm}$ are ablated [2]. The main imaging modalities for follow-up are CT, MRI, and PET-CT. Both a residual tumor and a recurrence during follow-up are defined in the term local tumor progression.

\section{Computed tomography}

Computed tomography is widely available and commonly used, but distinguishing normal post-ablation effects from residual disease and recurrence can be challenging. Some studies show that some CT features have the potential to indicate a high risk of local tumor progression [3-6]. An increase in the volume of the ablation zone during follow-up, > 4-6 months is highly suggestive for local tumor progression. Kele et al. showed that ablation zones without local recurrence all decreased in volume during follow-up ( $N=58$ patients and 117 lesions $)$ [5]. Wang et al. found that the risk for local tumor progression was smaller with the increasing volume of the ablation zone (i.e., a larger margin relative to the metastasis) and when the metastasis was more centrally treated, $(N=73$ patients and 117 lesions) [6]. This is in line with the general advice to achieve an ablation margin relative to the metastasis of at least $5 \mathrm{~mm}$ and preferably $10 \mathrm{~mm}$ [6, 7]. Morphological analysis of ablation zones on CT performed immediately after RFA might be helpful in detecting local residual tumor. Schraml et al. found that on the CT images made immediately after ablation, discontinuity of the ablation zone rim was indicative of residual tumor and local tumor progression. Additionally, irregularly shaped ablation zones had a tendency to 
Table 2 Recommended imaging protocol and follow-up schedule

\begin{tabular}{|c|c|c|c|}
\hline & Kidney & Liver & Lung \\
\hline Follow-up schedule & $\begin{array}{l}\text { First year: } 1,3,6,12 \text { months } \\
\text { Thereafter: every } 12 \text { months } \\
\text { (chest imaging every } 12 \text { months) }\end{array}$ & $\begin{array}{l}\text { First year: } 1,3,6,9,12 \text { months } \\
\text { Thereafter: every } 6 \text { months } \\
\text { Consider shortening of interval } \\
\text { in high risk patients or other } \\
\text { signs of recurrence }\end{array}$ & $\begin{array}{l}\text { First year: } 1,3,6,9,12 \text { months } \\
\text { (optional: before discharge after ablation) } \\
\text { Thereafter: every } 6 \text { months }\end{array}$ \\
\hline Recommended modalities & $\begin{array}{l}\text { 1. CT or MRI of the kidneys } \\
\text { 2. Biopsy only after } 6 \text { months } \\
\text { in case of suspected } \\
\text { recurrence }\end{array}$ & $\begin{array}{l}\text { 1. Primary MRI (mandatory after } \\
\text { TACE with Lipiodol), secondary CT } \\
\text { 2. PET-CT only for metastases }> \\
\text { 2cm and not for HCC } \\
\text { 3. PET-CT (if available) within } \\
\text { 48h after ablation } \\
\text { 4. PET-CT as a problem solver } \\
\text { and in case of suspected LTP } \\
\text { 5. Biopsy of ablation margin } \\
\text { can be considered in margins } \\
<5 \mathrm{~mm}(\rightarrow \text { optional to replace } \\
\text { MRI at } 6 \text { and } 12 \text { months by PET-CT) }\end{array}$ & $\begin{array}{l}\text { 1. CT } \\
\text { 2. PET-CT not before } 6 \text { months, } \\
\text { only in case of suspected recurrence } \\
\text { (and targeted biopsy for recurrence), } \\
\text { whole-body evaluation }\end{array}$ \\
\hline \multirow[t]{5}{*}{ Computed tomography } & unenhanced & unenhanced (HCC) & $\begin{array}{l}\text { unenhanced CT optional to establish } \\
\text { enhancement compared to baseline } \\
\text { late arterial (35s) after treatment }\end{array}$ \\
\hline & arterial phase (20-30s) & late arterial (35-40s) (HCC) & \\
\hline & nephrogenic phase (100s) & portal-venous (70s) (CRLM+HCC) & venous (70s) optional, if available \\
\hline & $\begin{array}{l}\text { delayed phase (10 min; to assess } \\
\text { complications) }\end{array}$ & late venous ( $\geq 120 s)$ (HCC) & \\
\hline & slice thickness maximally $3 \mathrm{~mm}$ & slice thickness maximally $3 \mathrm{~mm}$ & slice thickness 1 mm \\
\hline \multirow{7}{*}{$\begin{array}{l}\text { Magnetic resonance } \\
\text { imaging }\end{array}$} & axial T2W (with and without fatsat) & axial GRE in and opposed phase T1W & \\
\hline & axial and coronal dual echo & axial T2W FSE (with and without fatsat & \\
\hline & $\begin{array}{l}\text { axial dynamic 3D GRE before } \\
\text { and after Gd (20/70/180s) }\end{array}$ & $\begin{array}{l}\text { axial dynamic 3D fatsat GRE } \\
\text { before and after Gd (20/70/180s) }\end{array}$ & \\
\hline & axial 5 min post contrast GRE & $\begin{array}{l}\text { axial } 20 \text { min after hepatobiliary } \\
\text { specific Gd agent }\end{array}$ & \\
\hline & axial DWI & axial DWI & \\
\hline & & $\begin{array}{l}\text { subtraction images are highly } \\
\text { recommended for HCC }\end{array}$ & \\
\hline & & axial and coronal T2 HASTE & \\
\hline PET-CT & NA & $\begin{array}{l}\text { Only in CRLM: standard protocol } \\
\text { for FDG-PET-CT }\end{array}$ & standard protocol for FDG-PET-CT \\
\hline
\end{tabular}

Abbreviations: CT computed tomography, MRI magnetic resonance imaging, HCC hepatocellular carcinoma, transarterial chemoembolization, (FDG-)PET (fluorodeoxyglucose) positron emission tomography, LTP local tumor progression, CRLM colorectal liver metastases, GRE gradient echo, FSE fast spin echo, fat sat fat saturation, Gd gadolinium, DWI diffusion-weighted imaging, HASTE half-fourier acquisition single-shot turbo spin-echo

higher regrowth rates [4]. CT perfusion was shown to be helpful in a promising but very small study by Meijerink et al. $(N=10)$ : arterial hyperperfusion and portal venous hypoperfusion in the rim of the ablation zone were both associated with regrowth [8]. This approach is still highly experimental.

\section{FDG-PET-CT}

Several studies showed a benefit for PET-CT over CT in detecting local tumor progression after ablation [9-11]. Nielsen et al. showed that a rim-shaped FDG uptake 5 months after the ablation is predictive for local tumor progression, but this rim-shaped FDG uptake can be false-positive due to inflammation up to 4-6 months
[12]. Three studies with in total of 43 patients showed that PET-CT imaging shortly after RFA can be helpful in detecting complete ablation considering images are made before inflammation effects occur. Liu et al. performed PET/CT imaging within $24 \mathrm{~h}$, Khandani et al. within $41 \mathrm{~h}$, and Langenhoff et al. within 3 weeks after treatment [13-15]. Early PET-CT $(<48 \mathrm{~h}$ after ablation, e.g., in room immediate PET-CT) might overcome the false-positive findings at PET-CT later during follow-up.

MRI

Only 1 study that met our inclusion criteria was found for MRI in the follow-up after RFA. Kuehl et al. observed a comparable accuracy of MRI and PET/CT to 
Table 3 Imaging features during follow-up per intervention

\begin{tabular}{|c|c|c|c|c|c|}
\hline & $\begin{array}{l}\text { Thermal ablation } \\
\text { for CRLM }\end{array}$ & TARE for CRLM & TACE\&TARE for HCC & $\begin{array}{l}\text { Thermal ablation for } \\
\text { renal cancer }\end{array}$ & $\begin{array}{l}\text { Thermal ablation for } \\
\text { lung cancer }\end{array}$ \\
\hline$\overline{C T}$ & $\begin{array}{l}\text { * increase of ablation } \\
\text { zone size } \\
\text { * small size difference } \\
\text { between metastasis } \\
\text { and ablation zone } \\
\text { * ablation rim discontinuity } \\
\text { or irregular shape }\end{array}$ & $\begin{array}{l}\text { * Choi outperforms } \\
\text { RECIST } 1.1 \text { for } \\
\text { response assessment } \\
\text { * arterial perfusion has } \\
\text { potential to assess } \\
\text { response (reduction in } \\
\text { arterial perfusion predicts } \\
\text { outcome in liver mets, } \\
\text { not HCC) }\end{array}$ & $\begin{array}{l}\text { * residual arterial } \\
\text { enhancement } \\
\text { (thick, nodular or } \\
\text { irregular ring, } \\
\text { especially with } \\
\text { wash-out) }\end{array}$ & $\begin{array}{l}\text { * early peripheral } \\
\text { enhancing rim that } \\
\text { sustains after } 3 \text { months } \\
\text { * focal or nodular } \\
\text { enhancement at } \\
\text { ablation margin } \\
\text { (enhanced }>15 \mathrm{HU} \text { at CT } \\
\text { * increase in scar volume after } \\
2 \text { months post-ablation }\end{array}$ & $\begin{array}{l}\text { * increase in size of the } \\
\text { ablation scar } \\
\text { * appearance of nodular, } \\
\text { irregular, } \\
\text { eccentric solid component } \\
\text { in or at the margin of } \\
\text { ablation zone } \\
\text { * new contrast enhancement } \\
>15 \mathrm{HU}\end{array}$ \\
\hline MRI & $\begin{array}{l}\text { * increase of ablation } \\
\text { zone size } \\
\text { * small size difference } \\
\text { between metastasis } \\
\text { and ablation zon } \\
\text { same as on CT } \\
\text { * T2 moderate high } \\
\text { signal (focal, eccentric } \\
\text { or nodular) at the } \\
\text { margin } \\
\text { * persistent high } \\
\text { signal intensity } \\
\text { on high b-value } \\
\text { DWl and low ADC } \\
\text { * disruption of the } \\
\text { interface between } \\
\text { ablation zone and } \\
\text { liver parenchyma } \\
\text { * T1 hyperintensity } \\
>9 \text { months } \\
\text { * thickened or irregular } \\
\text { peri-ablation zone } \\
\text { tissue rim (low T1 } \\
\text { \& high T2) }\end{array}$ & $\begin{array}{l}\text { * DWI at } 4 \text { weeks can } \\
\text { predict outcome and } \\
\text { potentially can } \\
\text { outperform PET-CT } \\
\text { * caveat false positives } \\
\text { due to inflammation }\end{array}$ & $\begin{array}{l}\text { * same as for CT } \\
\text { * DWI and DCE seem } \\
\text { promising }\end{array}$ & $\begin{array}{l}\text { * same criteria as for } C T \\
\text { * enhancement: }>15 \% \\
\text { increase in signal intensity } \\
\text { on MRI is significant) } \\
\text { * after cryoablation: } \\
\text { interrupted T2 low intensity } \\
\text { rim }\end{array}$ & NA \\
\hline PET-CT & $\begin{array}{l}\text { * focal, eccentric } \\
\text { or rim shaped } \\
\text { FDG-uptake after } \\
4-6 \text { months post-ablation }\end{array}$ & $\begin{array}{l}\text { * reduction of } \geq 50 \% \text { in } \\
\text { SUVmax (FDG-PET-CT) } \\
\text { at } 4 \text { weeks predicts } \\
\text { outcome }\end{array}$ & NA & NA & $\begin{array}{l}\text { * new FDG uptake in } \\
\text { the scar }>6 \text { months } \\
\text { after ablation }\end{array}$ \\
\hline
\end{tabular}

Abbreviations: CRLM colorectal liver metastases, TACE transarterial chemoembolization, HCC hepatocellular carcinoma, TARE transarterial radioembolization, SIRT selective internal radiation therapy, $C T$ computed tomography, RECIST response evaluation criteria in solid tumors, $H U$ hounsfield units, MRI magnetic resonance imaging, DWI diffusion-weighted imaging, $A D C$ apparent diffusion coefficient, DCE dynamic contrast-enhanced, NA not applicable, $P E T$ positron emission tomography, FDG fluorodesoxyglucose; SUVmax maximum standardized uptake value, LTP local tumor progression

detect local tumor progression in a study of 16 patients with 20 lesions. They regarded new focal hypointense $\mathrm{T} 1$ lesions of focal T2 hyperintense lesions at the ablation margin as signs of LTP. Sensitivity and specificity were $73 \%$ and $100 \%$, respectively, for MRI and $84 \%$ and $100 \%$ for PET/CT [16]. A study by Kierans et al. (who evaluated a miscellaneous group of malignant liver lesions) showed that high signal intensity on unenhanced T1 $>9$ months after the procedure and well-defined enhancement was more frequently encountered in patients with LTP after RFA. For MWA, a low central signal intensity at unenhanced $\mathrm{T} 1$ accompanied with high $\mathrm{T} 1$ signal intensity at the edges was found frequently, regardless of response [17]. In a review by Sainani et al., focal, eccentric, nodular moderately hyperintense areas of T2 hyperintensity (with enhancement) were reported to be suspicious for LTP, just as disruption of the interface between ablation zone and liver parenchyma. Important pitfalls are postablation edema, apparent arteriovenous shunting, and neovascularization around the ablation zone, which are signs of inflammation and LTP [18]. Diffusion-weighted MRI has been sparsely evaluated, but Schraml et al. reported that it can be helpful in detecting LTP, but the false-positive high signal on b1000 images is often encountered and is thought to be caused by post-procedural changes around the ablation zone. Follow-up usually shows resolution of these findings if LTP is absent [19].

\section{Ultrasound}

Currently, there is no adequate evidence available for the use of ultrasound in the detection of local tumor progression after RFA for colorectal liver metastases [20]. 


\section{Ablation zone biopsy}

One study looked at the prognostic value of biopsy of the center and margin of the ablation zone immediately after treatment for time to local tumor progression. Viable tissue in the specimen of the biopsy was an independent risk factor for local tumor progression. In a multivariate analysis, a negative biopsy and an ablation margin of more than $5 \mathrm{~mm}$ predicted a recurrence risk of only $3 \%$ [7].

\section{Recommendations}

- MRI and PET-CT are the primary recommended modalities, CT is the secondary recommended modality

- MRI and PET-CT seem to be comparable in accuracy to detect local tumor progression, depending on the time point of follow-up

- PET-CT is superior to CT during follow-up after thermal ablation (RFA/MWA) to detect local tumor progression

- PET-CT seems most useful to detect local tumor progression shortly after ablation (24-48 h) or after 4 months

- PET-CT is only indicated for metastases $>2 \mathrm{~cm}$

- MRI might suffice with PET-CT as a problem solver or in case of suspected recurrence $>6$ months (mostly based on expert opinion)

o MRI protocol should consist of T2, T1, DWI, multiphasic post-contrast sequences, and delayed imaging in case Primovist is used

\section{Follow-up after TARE for CRLM}

TARE is mostly used as a treatment option in patients with (colorectal) liver metastases and HCC. Follow-up after liver-directed radioembolization of liver cancer (TARE) remains a challenge. The main problems for early response assessment are the inflammatory changes after high-dose radiation and generally delayed morphologic response to TARE on imaging. The main response assessment modalities consist of FDG-PET (CT), CT, and MRI.

\section{FDG-PET-CT}

A reduction in metabolic activity measured by SUVmax precedes the anatomical size reduction in metastatic colorectal cancer (CRLM) [21]. Other series in mixed histologies confirmed this finding and reported that FDG-PET detected responders 6 weeks after the intervention, while only $13 \%$ of these responders showed a reduction in size (partial response) on anatomical images [22]. More recent studies confirmed the prognostic role of early FDG-PET in CRLM after TARE. Four weeks after the intervention, a reduction of SUVmax of at least
$50 \%$ predicted a difference in survival of 10 months versus 4 months in CRLM [23]. More recently, advanced response criteria (PERCIST) have been evaluated to assess response in TARE patients. A change in SUVpeak and total lesion glycolysis predicted overall survival $(p=$ 0.039 ; hazard ratio $[\mathrm{HR}], 0.24 ; 95 \%$ confidence interval $[\mathrm{CI}], 0.06-0.93)$, progression-free survival $(p=0.016$; $\mathrm{HR}, 0.15$; 95\% CI, 0.03-0.69), and time to intrahepatic progression ( $p=0.010 ; \mathrm{HR}, 0.16$; 95\% CI, 0.04-0.65) [24]. Interestingly, in the same study, summed baseline CT diameter of less than $8 \mathrm{~cm}$ for the 2 largest liver metastases predicted time to intrahepatic progression $(p=$ 0.013; HR, 0.21; 95\% CI, 0.06-0.72) but did not predict overall or progression-free survival [24]. Overall, the body of evidence supports that a reduction of FDG avidity in early PET (4 weeks) might be useful to predict the further outcome of the patients.

\section{Computed tomography}

CT relies mainly on size criteria for response assessment (RECIST 1.1), which is difficult to use as a response criterion, as it does not take into account the necrosis, cystic degeneration, and edema that occurs [25]. A recent study investigating different criteria found that RECIST 1.1 after TARE is not suitable to assess response in these patients. Alternatively, Choi criteria and difference in tumor attenuation can predict outcome after TARE in CRLM patients and has the same predictive power as the EORTC PET response criteria [26]. More recently, arterial perfusion (AP) $\mathrm{CT}$ was investigated to predict and prognosticate outcome in TARE patients. A study by Reiner et al. showed a reduction of AP in early CT after TARE as the predictor for outcome in patients with liver metastases. Other studies measured AP of the entire tumor volume via voxel-wise histogram analysis [27]. AP derived from histogram analysis was significantly different in responders versus non-responders. Overall, the paradigm that CT might not be an imaging of choice due to the restrictions of RECIST 1.1 has to be re-challenged in the light of new response criteria and more advanced protocols as arterial perfusion protocols. Future studies are needed to determine the most suitable imaging modality after TARE.

\section{MRI}

Enhancement around a treated lesion after TARE can be found on MRI and is usually found when the follow-up scan is performed early ( $<3$ months after TARE) and then corresponds to inflammation. It can be present in the whole treated area. It is important not to mistake this as a viable tumor or progression and take into account the time from the treatment to follow-up. Recent studies focused on predicting outcome using differences in the apparent diffusion coefficient (ADC) on diffusion- 
weighted imaging (DWI) [28]. A study investigated 44 CRLM patients who underwent DWI before and around 1 month after TARE. An increase of the minimal ADC (minADC) of more than $22 \%$ could independently predict the overall survival (18 vs. 5 months; $p<0.001$ ), together with hepatic tumor burden [29]. DWI-MRI before and 6 weeks after TARE showed a higher positive predictive and a higher negative predictive value for the detection of response compared to FDG-PET (96\% versus $88 \%$; $96 \%$ versus $56 \%$ ). Overall, the detection of response was higher for DWI-MRI than for FDG-PETCT $(96 \% ; 22 / 23$ versus $65 \% ; 15 / 23)(p<0.02)$ [29]. So, DWI-MRI might outperform early FDG-PET to detect progression or predict long-term outcome.

\section{Radiation-induced changes in the liver due to TARE}

Y90 radiation-mediated damage is mostly related to the endothelial lesion that later provokes epithelial damage [30]. After Y90 radioembolization some of the changes in the tumor that are not related to the size changes may reflect tumoral response or progression. The appearance of hemorrhagic necrosis after the treatment can induce tumor growth that is not related to progression [31]. Furthermore, despite the fact that lack of humoral enhancement can be considered as a marker of response, its absence is not a sign indicating failure of the treatment [26]. There are also other changes that do not imply any oncological meaning and that are normal reaction to the radiation, these changes include peritumoral edema, peripheral rim enhancements (of $<5$ $\mathrm{mm}$ thickness), poorly defined areas of hypoattenuation, volumetric changes (typically ipsilateral atrophy with contralateral hypertrophy when selective treatments), capsular retraction without cirrhosis (in metastatic non-cirrhotic livers), and perihepatic and pleural effusion [32].

\section{Conclusion}

Initially, early (4 weeks) FDG-PET-CT or DWI-MRI seemed to be a good method to assess response and outcome after TARE in CRLM. However, enhancementbased parameters on MRI and CT (such as Choi and possibly assessment of arterial perfusion) might be of value as a stand-alone or complementary modality. Studies are still sparse and efforts should be made to run prospective clinical trials to better assess the available modalities and harmonize response criteria and follow-up.

\section{Recommendations}

- FDG-PET-CT is recommended to assess early response 4 weeks after TARE in CRLM
- Size-based criteria using RECIST 1.1 are not reliable for follow-up of patients, while ceCT with the use of Choi criteria might be a suitable alternative

- Early contrast-enhancement on MRI is usually caused by inflammation and diffusion-weighted imaging can help distinguish inflammation from tumor

- Arterial perfusion on ceCT has the potential to assess response, but new studies need to confirm these findings

\section{Follow-up after TACE or TARE for HCC}

Locoregional treatment of hepatocellular carcinoma (HCC) nowadays consists mainly of intra-arterial therapies: transarterial chemoembolization (TACE) and transarterial radioembolization (TARE). Early detection of residual tumor or recurrence leads to better outcomes [33]. Because of the complexities in therapeutic approaches, a therapy-tailored imaging evaluation of HCC after therapy is of paramount importance [34]. Focus is aimed at the margins of the treated area and on the viability of the treated tissue. Currently, EASL and mRECIST criteria are recommended for response assessment in HCC and can be used on dual-phase MRI or CT (arterial and portal venous phase) [35] and take into account size and vascularity.

\section{Computed tomography}

CT has long been the mainstay in HCC imaging for both initial tumor characterization and post-treatment followup. After locoregional treatment, a central area of coagulative necrosis with transient surrounding hyperemia is often seen and both will mostly resolve during followup. This coagulative necrosis will result in hyperdensity on unenhanced CT. Transient hyperemia is a physiologic reaction and manifests as a thin, uniform enhancement of the treated zone. After TARE, this can be visible in the whole treated area. However, small foci of the residual tumor may be obscured by transient hyperemia. Therefore, persistent arterial enhancement with washout on delayed phase images can indicate residual tumor or recurrence. Any nodular or thick areas of arterial enhancement along the treatment margin are very suspicious for residual tumor or recurrence, especially if there is a washout. In a recent retrospective study, a lack of tumor enhancement and peripheral ring enhancement showed a low risk for progression, while peripheral nodular enhancement on arterial phase CT after TACE with drug-eluting beads was associated with a likelihood of $83 \%$ for tumor progression [36]. In inconclusive cases regarding residual tumor or recurrence, an additional follow-up after 3 months is advised.

After TACE using Lipiodol, unenhanced CT can be performed to assess Lipiodol distribution. In general, complete retention of iodized oil has a high correlation 
with complete lesion necrosis, while incomplete retention of Lipiodol can be related to both necrosis and residual viable tumor $[35,37]$. Lack of iodized oil uptake immediately after therapy may also indicate an aberrant vascular supply to the tumor and will require repeated treatment as soon as possible. Multiphasic MDCT must still be performed to further assess the areas lacking iodized oil for enhancement and washout [38]. Necrotic nonviable tumor tissue will continue to retain the oil indefinitely but will decrease in size over time. Volumetric assessment of the treatment zone is particularly helpful in cases in which necrosis is heterogeneously distributed in HCC and mRECIST is less suitable for response assessment $[39,40]$. Additionally, per voxel analysis of the enhancement of the tissue might increase accuracy for response monitoring after TACE for HCC, but this has only been suggested in a small retrospective study [41]. Perfusion CT gives the opportunity to capture CT attenuation as a function of time, which can be used to quantify tissue and tumor vascular characteristics. TACE reduces tumor blood volume, which will lead to a significant decrease in hepatic arterial fraction and perfusion in tumors effectively treated by TACE. In a recent study from $\mathrm{Su}$ et al. (prospective study, $n=39$, perfusion $\mathrm{CT}$ performed before cTACE) found that the responders (mRECIST criteria) demonstrated higher hepatic arterial perfusion (HAP) and lower hepatic portal perfusion (HPP) compared to non-responders among the 34 lesions without portal vein tumor thrombus. So far, the evidence is limited and clinical value of arterial perfusion is yet to be established.

\section{MRI}

The coagulative necrosis that occurs will lead to a hyperintense signal on unenhanced T1-weighted imaging. Subtraction images can be a helpful adjunct for differentiating hemorrhage from enhancing tumor on MRI [42, 43]. MR has been shown to be advantageous in assessing treatment-related changes in HCC (mainly post-contrast T1W MRI and DWI) and is superior to ceCT in evaluating patients who have undergone Lipiodol-based TACE therapies. Lipiodol does not adversely affect MR signal intensity, while beam-hardening effects on CT may obscure small enhancing tumors $[44,45]$. Therefore, MRI is recommended when lipiodol-based TACE has been performed. The added value of gadoxetic acid over extracellular GBCAs after HCC locoregional therapy is unclear. Diffusion-weighted imaging can be of help in distinguishing viable from necrotic areas after HCC treatment. Residual diffusion restriction is suggestive of residual viable tumor. Combining DWI with conventional MRI can increase sensitivity for detecting viable tumor [44]. Sensitivity for detection of (residual) HCC does not improve and one study even reported a poorer diagnostic performance compared to contrast-enhanced multiphasic T1W MRI [46]. Conflicting results have been reported regarding the value of pre-treatment ADC measurements $[47,48]$. There might be a value for ADC measurements after treatment, as two studies found that an increase in ADC after treatment was associated with good response [47, 48]. There is some preliminary evidence for dynamic contrast-enhanced (DCE-MRI; in which images are continuously acquired to assess perfusion by obtaining a signal-intensity-time curve) for response assessment after TACE for HCC, but the evidence is too sparse to recommend its use [49]. Future trials will have to provide evidence of the value of DCEMRI.

\section{FDG-PET-CT}

HCCs are often non-FDG-avid. FGD-PET has limited value in HCCs due to its limited sensitivity for HCC detection of around 60\% [43]. However, one study published that when an HCC is FDG-avid, metabolic responders survived longer than non-responders (10 vs. 5 months, respectively) [50]. Currently, FDG-PET is not recommended in HCC.

\section{Ultrasound}

Ultrasound is generally used for HCC screening and is not recommended for follow-up of patients with treated HCC. Contrast-enhanced EUS (CEUS) has shown potential for the detection of small foci of residual tumor after TACE [51] Also, CEUS can be used during or immediately after locoregional therapy. Until now, no convincing evidence has been published to support the use of CEUS in clinical practice for HCC $[51,52]$.

\section{Recommendations}

- MRI is the recommended follow-up modality; CT is the next best modality

- MRI is mandatory when conventional TACE with lipiodol has been performed, multiphasic CT can be performed to assess lipiodol distribution

- CT protocol should include a quadruple-phase CT protocol including unenhanced images

- There is no (established) role for PET-CT or (contrastenhanced) ultrasound in follow-up

- During follow-up, modified RECIST or EASL criteria should be the basis to identify recurrence

- Sufficient evidence is lacking on new techniques such as DWI/DCE-MRI and perfusion CT but these techniques seem promising

4. Follow-up schedules after locoregional treatment of the liver Due to the limitations of ceCT, PET-CT, and MRI are recommended modalities to monitor the treatment zone 
in CRLM. Nielsen et al. suggested a 3-6 monthly followup scheme with PET-CT for the first year after RFA. However, they reported that PET-CT might be of minimal value in follow-up after ablation of $<2 \mathrm{~cm}$ lesions, as the risk for local tumor progression is very low [12]. Kuehl et al. proposed the following follow-up protocol: immediately after treatment PET-CT is more useful than MRI, at 4 weeks MRI is preferred, at 3 months MRI is comparable to PET-CT (which would make MRI the preferred modality), after 6 months and 1 year PET-CT and MRI are both valuable modalities with PET-CT having the benefits of whole-body screening [16]. Thus, a combination of PET-CT with MRI was recommended.

For HCC, the proposed surveillance schedules after liver-directed therapy include: at 1 month and every 3 months thereafter, or with the interval stretched to every 6 months after 1-year post-treatment.

Closer follow-up or immediate imaging may be indicated in case of a high risk for local recurrence if there is suspicion for incomplete treatment, equivocal imaging findings, new clinical symptoms, rising alphafetoprotein, or other abnormal laboratory test values. This is consistent with previous work showing that the optimal time between scans is approximately proportional to the reciprocal of the square root of the probability of recurrence. Boas et al. $(N=1766$ consecutive TACE, TARE, and RFA procedures in 910 patients) showed that recurrence is 6.5 times more likely in the first year after treatment, compared to the second year after treatment [46]. Furthermore, they showed that more frequent follow-up screening than the minimum published recommendation is cost-effective.

\section{Recommendations for follow-up schedule (Table 2):}

- Imaging at 1, 3, 6, 9, 12 months in the first year and every 6 months in the subsequent years

- In patients with a high risk for recurrence (ex. infiltrative type, irregular necrosis after TACE, or poor lipiodol deposition after cTACE), some evidence exists to shorten follow-up intervals in the first year in $\mathrm{HCC}$

- In case of other indications for a recurrence (e.g. increasing CEA in CRLM or equivocal findings on imaging), an additional follow-up moment can be scheduled

\section{B. Follow-up after thermal ablation for renal cancer}

Thermal ablation for renal cancer is considered a therapeutic option if complete ablation can reliably be achieved [53]. Radiofrequency ablation (RFA), cryoablation, and microwave ablation (MWA) are options in ablation for renal cancer. The visualization of the physical changes caused by freezing whether using CT, MRI, or ultrasound seems to be a major advantage of cryoablation [54, 55]. This could be useful for monitoring the treatment when the lesion to be treated is close to sensitive organs or structures.

Both CT and MRI may be used for follow-up after renal ablation [56-59]. (FDG-)PET-CT does not play a role in renal cancer, due to the low FDG avidity of RCCs. Close follow-up is usually performed in the first year after ablation at a frequency of 3-4 examinations progressively spaced, often at $1,3,6$, and 12 months. Then, an annual follow-up is recommended for at least 5 years but often more. Follow-up imaging at 1 month after ablation is recommended to assess for complications and set baseline for future follow-up. Imaging follow-up has to detect any complications occurring after renal ablation in particular on the first scans [60-63]. Major complication rates do not differ statistically between cryoablation (7.7\%) and RF ablation (4.7\%) [64]. If there is a concern for incomplete treatment, then a 3-month follow-up is recommended to prepare for second treatment as an early peripheral enhanced rim may be observed on CT or late MR sequences possibly in relation to inflammatory changes within the few weeks after treatment. Often located on the margins of an ablation, the presence of focal nodular enhancement remains the only validated imaging pattern of residual tumor tissue or recurrence. This requires scanning without, and then with the injection of contrast product.

On CT, the evaluation of the enhancement remains qualitative and quantitative. Any contrast enhancement of more than $15 \mathrm{HU}$ should be considered significant $[57,65]$. On MRI, due to the spontaneous high T1W signal intensity of the ablation zone, subtraction techniques must be used to detect or eliminate focal enhancement on margins. Quantitatively, an enhancement is considered significant on MRI if it exceeds $15 \%$ on the dynamic contrast-enhanced sequence [56]. After cryoablation, a more sustainable low T2W signal intensity rim can be observed [66]. Interruption of this rim might indicate a residual tumor. If complete treatment was performed, then a 12-month contrast-enhanced CT or MR is suggested including chest CT. Changes in the size of the treated site are observed. A volume increase is observed early and up to the first 2 months after the procedure, more particularly for small tumors less than 3 $\mathrm{cm}^{3}$ [67]. Then the volume of the scar may gradually decrease until 1 to 2 years. Involution of the ablation zone is more frequently observed after cryoablation. On CT and MRI, infiltration of peripheral fat is almost systematic, especially for exophytic tumors $[67,68]$. A spontaneously dense and low T1W signal intensity peripheral halo is observed in nearly $75 \%$ of cases and appears during the first months and often persists [68]. Invagination of fat in the scar is rare and occurs later [67]. Renal 
ablation zone soft-tissue nodules from fat necrosis can appear long after ablation, enhance with contrast medium, mimic applicator tract or ablation zone tumor seeding, and may require biopsy for confirmation of benignity [69]. If necessary, biopsies should be performed 6 months after ablation and should not be systematic, based on a case-by-case discussion based on imaging findings $[60,69]$.

\section{Recommendations}

- Follow-up imaging at 1 month after ablation to assess for complications and set baseline for future follow up by CT or MRI

- If there is a concern for incomplete treatment at 1 month, a 3-month follow-up is recommended to evaluate the need and prepare for a second treatment

- If complete treatment was performed, follow-up is recommended at 6 and 12 months

- Annual contrast-enhanced CT or MR are suggested up to 5 years

- If concern for recurrence, consider biopsy to confirm

\section{Follow-up after thermal ablation of lung tumors Computed tomography}

CT remains the most often used technique for follow-up after thermal ablation for lung tumor with radiofrequency ablation (RFA), microwave ablation (MWA), or cryoablation (CRA). An increase in the size of the ablation zone is usually observed during the early postablation period because of inflammatory changes and hemorrhage. Before 6 months, the ablated area is supposed to exceed the size of the tumor before ablation [70]. Normally, the scar decreases moderately in size during follow-up but may remain almost stable after 6 months [71-73]. The definite scar is often equal to or bigger than the initial tumor. The baseline measurement of the ablation zone should be done 1 month after ablation on CT [70, 74-79]. RECIST evaluation after RFA or MWA in comparison to the baseline scan is not effective, due to the limitations of size measurements after ablation. After cryoablation, the downsizing of the ablation zone seems to be faster [80], so that size has a potential value during follow-up, measuring its surface [81], using RECIST [82], or WHO criteria [80]. In cases where the ablation zone remains stable, analysis of contrast enhancement is useful in the determination of the effectiveness of lung ablation [70, 75, 76, 78, 83]. When compared to pre-contrast CT, an increase of attenuation of at least $15 \mathrm{HU}[82,84-86]$ or $25 \mathrm{HU}[74,79]$ is described as suggestive of incomplete ablation. Apart from contrast uptake, any increase in size, nodular, irregular, or eccentric solid component appearing within or at the edge of the ablation zone, by comparing to the previous CT image, should be considered as a local recurrence [70, 72, 74, 76, 78, 85, 87, 88]. Early CT follow-up (until the 6th month) may demonstrate enlargement of hilar and mediastinal lymph nodes frequently (almost $60 \%$ of treated patients) with common reversibility as a result of the reactive change [89]. All these arguments support that CT should be performed with contrast injection. Recent technical improvements can be used to optimize the results of CT: dual-energy CT may help in the diagnosis of early recurrences after RF ablation [90] and perfusion CT performed pre- and postoperatively may be useful in the determination of adequate treatment after MWA [91].

\section{FDG-PET-CT}

PET-CT has been described as a useful method during follow-up after lung ablation [76, 92-96]. When PET is not regularly scheduled, it is mainly performed when local recurrence is suspected or systemic progression needs to be evaluated. In a prospective study, Bonichon et al. demonstrated the low specificity of PET-CT at the early period ( 3 months) after RF lung ablation, due to the high number of false- positive results [97], which was confirmed in another study evaluating follow-up of the ablation zone [92]. In a small cohort of 18 patients treated by RF and followed up for 24 months, SUV was described as a poor indicator of local recurrence since it may be equal to or greater than baseline SUV in almost half of the patients in the center of the ablation zone [98].

\section{MRI}

MR after lung ablation is only reported in a few recent preliminary studies, dedicated to early evaluation after RF [99] or MW [100]. A few years ago, another report described a short prospective series showing that early diffusion MR 3 days after RF may predict further local progression [101].

\section{Recommendations}

- Contrast-enhanced CT is the preferred modality

- PET-CT is recommended > 6 months after ablation, due to the high rate of false-positive results before 6 months

- PET-CT should be used when local progression is suspected at CT, when the whole-body evaluation is required, or to precisely target a suspected recurrence for biopsy.

- A contrast-enhanced CT is recommended before discharge of the patient to provide baseline 
measurements of the ablation zone and detect early complications

- A contrast-enhanced CT 1 month after ablation is recommended as baseline for further follow-up

- After 1 month, the ablation zone is expected to remain homogeneous without any significant enhancement, with gradual decrease in size and regular margins.

- After 6 months, the treated lesion may remain stable or slightly decrease in size after RFA or MWA. Shrinkage after cryoablation is usually more profound.

- Dual-energy CT, perfusion CT, and thoracic MR will possibly play a role in patient's surveillance after lung ablation, but are still under investigation.

\section{Discussion}

This paper presents recommendations based on expert opinion and evidence on follow-up after interventional radiological treatment for liver cancer, renal cancer, and lung cancer. Only limited evidence is available from small studies. The main aims of follow-up are identifying residual tumor/assessment of response, detecting recurrence and new tumors or metastases. CT, MRI, and (FDG-)PET-CT are the main modalities useful for follow-up. One of the main issues is that after oncological interventions standard RECIST 1.1 response assessment is not reliable and other response criteria should be used. Additionally, efforts should be made to evaluate new imaging techniques to further improve response assessment (e.g., exploration of DWI, DCE-MRI, perfusion CT).

All experts agreed that for all cancers discussed in this paper, follow-up at 1 month should be performed after the intervention to identify complications and possible residual tumor. After 1 month, the subsequent follow-up schedule is most strict for liver cancer compared to lung and renal cancer. For liver cancer, a follow-up schedule with imaging at 1, 3, 6, 9, 12 months and 6 monthly thereafter was proposed. Contrast-enhanced CT is mostly used in liver cancer in clinical practice but is not recommended by the panel as the primary modality. Even though CT is widely available, it can be performed quickly and is the modality that radiologists have most expertise with, MRI is the modality of choice for local evaluation in the liver mainly because its superiority to detect smaller lesions than CT. Furthermore, MRI does not require radiation or iodine contrast and in the specific issue of HCC, MRI is superior to ceCT when Lipiodol is used. When MRI is not easily available or there is a strong preference for CT in clinical practice, CT can be considered as well. In case of extrahepatic metastases that require monitoring with CT (e,g. for RECIST 1.1. evaluation), CT will be the modality of choice instead of
MRI. During follow-up, it is not recommended to change modality as this can hamper comparability between two exams. For CT, texture analyses are currently under study and in due time this might be used in daily practice [102]. PET-CT can be considered in CRLM, but not for HCC. PET-CT is recommended as a problem solver and provides the advantage of high accuracy to detect extrahepatic metastases [103]. In the liver, hematoma and post-intervention changes can lead to false-positive DWI signal and FDG uptake in and around the treated area, and radiologists should be aware of these pitfalls when performing follow-up. For this reason, PET-CT is not recommended for the first 4-6 months after ablation for CRLM (unless it is performed within $48 \mathrm{~h}$, but this is not available in most centers). After TARE, little evidence is available for follow-up, but PET-CT seems the most accurate early (4 weeks) modality for response evaluation for CRLM, as MRI can be false-positive due to inflammation early after TARE. DWI seems to be the best modality to identify local tumor progression. CT is the second recommended modality. RECIST 1.1 is not accurate for response assessment. Based on expert opinion the panel recommended Choi criteria as an alternative method for response assessment after TARE over RECIST 1.1, when using CT for follow-up. Even though, this still is suboptimal response assessment criteria (primarily developed for gastro-intestinal stromal tumor and low reproducibility), the panel did consider the Choi criteria superior to RECIST 1.1 [104-106].

For renal cancer, the follow-up schedule is less intensive but includes a 1, 3 (optional), 6 and 12-month follow-up in the first year, and after 1 year of follow-up, annual follow-up suffices. In renal cancer, both CT and MRI can be considered for follow-up and are considered equal in diagnostic performance during follow-up. PETCT has no role as RCCs tend not to be FDG-avid.

For lung cancer, 1-month post-ablation contrastenhanced CT is recommended and ceCT is the mainstay of follow-up. Just as for liver imaging, PET-CT should not be performed early after the intervention, given the risk for false-positive findings. PET-CT should be regarded as a problem solver and should be used when a recurrence is suspected.

A complicating factor in research on response assessment after the oncological intervention is the lack of a solid gold standard. Histopathology is rarely available and, therefore, the gold standard is constituted of (multiple) imaging modalities, which makes it very challenging to establish a good validation of imaging modalities. To improve the gold standard, a long followup interval is then needed, making these kinds of trials less appealing and cumbersome to execute. Efforts should be made to identify other validation techniques 
that are accurate and easy to use in clinical practice. The rapid development in interventional oncology treatments, but also in diagnostic techniques, stresses this need for a good gold standard and validation even more, in order to effectively incorporate new interventions into practice. Practically, when there is uncertainty in a clinical setting, a biopsy can always be considered in individual cases to provide more information (even though sampling error can be encountered due to difficulty to target the potential residual viable tissue in areas of necrosis after treatment).

The lack of high-quality prospective studies is an issue that needs attention. So far, small (sometimes) retrospective studies have been performed, without emphasis on follow-up modalities and schedules. Most studies in interventional radiology aim at evaluating success rates of procedures and follow-up is then usually performed with standard techniques, i.e., usually $\mathrm{CT}$, which is known to have limitations, as discussed in this paper. However, from a diagnostic point of view, follow-up is important and should be evidence based and as accurate as possible. To improve this issue, it is advisable that interventional radiologists and diagnostic radiologist join efforts to improve research on response assessment after interventional radiology for cancer.

This consensus paper focuses on local treatment evaluation, but for follow-up metastases outside the treated organ should be considered as well. For CRLM and lung cancer, $\mathrm{CT}$ of the thorax and abdomen or PET-CT can be considered for distant staging. For renal cancer, $\mathrm{CT}$ is advisable (of the thorax and abdomen).

\section{Limitations}

These recommendations have been constructed by use of evidence if available, but unfortunately, the quality and amount of evidence were limited. Therefore, the currently presented recommendations are partly based on expert opinion and consensus, which is the highest level of evidence available for some issues. We did not discuss who is responsible for follow-up: the interventional radiologist or the primary treating physician (e.g., surgeon, urologist, gastro-enterologist, or pulmonologist). It is important to prevent redundant follow-up, and therefore, interventional radiologists should make an effort to have a multidisciplinary follow-up protocol in their hospital in which it is clear who takes responsibility for follow-up. Last, thermal ablation of HCC was not discussed for which the LI-RADS treatment response algorithm is available [107].

\section{Conclusion}

For liver cancer, renal cancer, and lung cancer, a followup schedule could be proposed after the oncologic intervention. PET-CT, CT, and MRI are the modalities of choice, but one should beware of false-positive signs of residual tumor or recurrence due to inflammation early after the intervention. Next to local evaluation, wholebody staging should be used as well, to identify lesions outside the targeted organ. The lack of high-quality evidence stresses the need for high-quality research on follow-up after radiological intervention in oncology and an accurate gold standard, especially with emerging new interventional and diagnostic techniques. For now, these recommendations can be used in clinical practice to guide the follow-up of patients that had a radiological intervention for liver cancer, lung cancer, and renal cancer.

\section{Abbreviations \\ ADC: Apparent diffusion coefficient; AP: Arterial perfusion; ceCT: Contrast- enhanced computed tomography; CEUS: Contrast-enhanced ultrasound; CRLM: Colorectal liver metastases / metastatic colorectal cancer; DCE- MRI: Dynamic contrast-enhanced magnetic resonance imaging; DWl: Diffusion-weighted imaging; ECIO: European conference on interventional oncology; ESOI: European society of oncologic imaging; FDG- PET: Fluorodesoxyglucose positron emission tomography; GBCA: Gadolinium- based contrast agents; HCC: Hepatocellular carcinoma; HR: Hazard ratio; ICC: Intrahepatic cholangiocarcinoma; LTP: Local tumor progression; MDCT: Multi-detector computed tomography; mRECIST: Modified response evaluation criteria in solid tumors; MWA: Microwave ablation; PERCIST: PET Response Criteria in Solid Tumors; RCC: Renal cell cancer; RECIST: Response evaluation criteria in solid tumors; RFA: Radiofrequency ablation; SUVmax: Maximal standardized uptake value; TACE: Transarterial chemoembolization; TARE: Transarterial radioembolisation; Y90: Yttrium-90}

Authors' contributions

All authors fulfill the criteria that allow for authorship. The author(s) read and approved the final manuscript.

\section{Funding}

None

Availability of data and materials

Evidence-based recommendations, no patient materials involved.

Ethics approval and consent to participate

Ethics approval are not applicable.

Consent for publication

All authors consented to the publication.

\section{Competing interests}

Dr Solomon provided the following conflicts of interest. Consulting: BTG, Johnson \& Johnson, Aperture Medical, XACT Robotics, Varian. Research Grants: GE Healthcare, Elasta, AngioDynamics. Shareholder: Aspire Bariatrics, Aperture Medical, Johnson \& Johnson, Immunomedics, Impulse Dynamics, MOTUS GI, Progenics. The remaining authors have none.

\section{Author details}

'Dept of Radiology, The Netherlands Cancer Institute, Amsterdam, The Netherlands. ${ }^{2}$ Dept of Radiology, CHU Hospital Timone, Marseille, France. ${ }^{3}$ Aix Marseille Univ, LIIE, Marseille, France. ${ }^{4}$ Dept of Radiology, Hospital Clinic de Barcelona, Barcelona, Spain. ${ }^{5}$ Dept of Radiology, S. João University Hospital, Porto, Portugal. ' Dept of Radiology, Lausanne University Hospital, Lausanne, Switzerland. ${ }^{7}$ Dept of Radiology, Memorial Sloan Kettering Cancer Center, New York, USA. ${ }^{8}$ Dept of Radiology, University Clinic of Navarra, Calle Benjamín de Tudela, 2, 31008 Pamplona, Navarra, Spain. 
Received: 14 May 2019 Accepted: 20 May 2020

\section{Published online: 16 July 2020}

\section{References}

1. Swartz MK (2011) The PRISMA statement: a guideline for systematic reviews and meta-analyses. J Pediatr Health Care. 25(1):1-2

2. Gillams A, Goldberg N, Ahmed M et al (2015) Thermal ablation of colorectal liver metastases: a position paper by an international panel of ablation experts, The Interventional Oncology Sans Frontieres meeting 2013. Eur Radiol. 25(12):3438-3454

3. Frich L, Hagen G, Brabrand K et al (2007) Local tumor progression after radiofrequency ablation of colorectal liver metastases: evaluation of ablative margin and three-dimensional volumetric analysis. J Vasc Interv Radiol. 18(9):1134-1140

4. Schraml C, Clasen S, Schwenzer NF et al (2008) Diagnostic performance of contrast-enhanced computed tomography in the immediate assessment of radiofrequency ablation success in colorectal liver metastases. Abdom Imaging. 33(6):643-651

5. Kele PG, de Jong KP, van der Jagt EJ (2012) Increase in volume of ablation zones during follow-up is highly suggestive of ablation site recurrence in colorectal liver metastases treated with radiofrequency ablation. J Vasc Interv Radiol. 23(4):537-544

6. Wang X, Sofocleous CT, Erinjeri JP et al (2013) Margin size is an independent predictor of local tumor progression after ablation of colon cancer liver metastases. Cardiovasc Intervent Radiol. 36(1):166-175

7. Sotirchos VS, Petrovic LM, Gonen M et al (2016) Colorectal Cancer Liver Metastases: Biopsy of the Ablation Zone and Margins Can Be Used to Predict Oncologic Outcome. Radiology. 280(3):949-959

8. Meijerink MR, van Waesberghe JH, van der Weide L et al (2009) Early detection of local RFA site recurrence using total liver volume perfusion CT initial experience. Acad Radiol. 16(10):1215-1222

9. Veit $P$, Antoch G, Stergar H, Bockisch A, Forsting M, Kuehl H (2006) Detection of residual tumor after radiofrequency ablation of liver metastasis with dual-modality PET/CT: initial results. Eur Radiol. 16(1):80-87

10. Sahin DA, Agcaoglu O, Chretien C, Siperstein A, Berber E (2012) The utility of PET/CT in the management of patients with colorectal liver metastases undergoing laparascopic radiofrequency thermal ablation. Ann Surg Oncol. 19(3):850-855

11. Travaini $L L$, Trifiro G, Ravasi $L$ et al (2008) Role of [18F]FDG-PET/CT after radiofrequency ablation of liver metastases: preliminary results. Eur J Nucl Med Mol Imaging. 35(7):1316-1322

12. Nielsen $K$, van Tilborg AA, Scheffer HJ et al (2013) PET-CT after radiofrequency ablation of colorectal liver metastases: suggestions for timing and image interpretation. Eur J Radiol. 82(12):2169-2175

13. Liu ZY, Chang ZH, Lu ZM, Guo QY (2010) Early PET/CT after radiofrequency ablation in colorectal cancer liver metastases: is it useful? Chin Med J (Engl). 123(13):1690-1694

14. Khandani AH, Calvo BF, O'Neil BH, Jorgenson J, Mauro MA (2007) A pilot study of early 18F-FDG PET to evaluate the effectiveness of radiofrequency ablation of liver metastases. AJR Am J Roentgenol. 189(5):1199-1202

15. Langenhoff BS, Oyen WJ, Jager GJ et al (2002) Efficacy of fluorine-18deoxyglucose positron emission tomography in detecting tumor recurrence after local ablative therapy for liver metastases: a prospective study. J Clin Oncol. 20(22):4453-4458

16. Kuehl H, Antoch G, Stergar H et al (2008) Comparison of FDG-PET, PET/CT and MRI for follow-up of colorectal liver metastases treated with radiofrequency ablation: initial results. Eur J Radiol. 67(2):362-371

17. Kierans AS, Elazzazi M, Braga L et al (2010) Thermoablative treatments for malignant liver lesions: 10-year experience of MRI appearances of treatment response. AJR Am J Roentgenol. 194(2):523-529

18. Sainani NI, Gervais DA, Mueller PR, Arellano RS (2013) Imaging after percutaneous radiofrequency ablation of hepatic tumors: Part 2. Abnormal findings. AJR Am J Roentgenol. 200(1):194-204

19. Schraml C, Schwenzer NF, Clasen S et al (2009) Navigator respiratorytriggered diffusion-weighted imaging in the follow-up after hepatic radiofrequency ablation-initial results. J Magn Reson Imaging. 29(6): 1308-1316

20. Eisele RM, Schumacher G, Lopez-Hanninen E, Neuhaus P (2007) Role of Bmode ultrasound screening in detection of local tumor recurrence in the first year after radiofrequency ablation in the liver. Cancer Detect Prev. 31(4): $316-322$
21. Lewandowski RJ, Thurston KG, Goin JE et al (2005) 90Y microsphere (TheraSphere) treatment for unresectable colorectal cancer metastases of the liver: response to treatment at targeted doses of 135-150 Gy as measured by [18F]fluorodeoxyglucose positron emission tomography and computed tomographic imaging. J Vasc Interv Radiol. 16(12):1641-1651

22. Szyszko T, Al-Nahhas A, Canelo R et al (2007) Assessment of response to treatment of unresectable liver tumors with 90Y microspheres: value of FDG PET versus computed tomography. Nucl Med Commun. 28(1):15-20

23. Sabet A, Meyer C, Aouf A et al (2015) Early post-treatment FDG PET predicts survival after $90 \mathrm{Y}$ microsphere radioembolization in liver-dominant metastatic colorectal cancer. Eur J Nucl Med Mol Imaging. 42(3):370-376

24. Michl M, Lehner S, Paprottka PM et al (2016) Use of PERCIST for Prediction of Progression-Free and Overall Survival After Radioembolization for Liver Metastases from Pancreatic Cancer. J Nucl Med. 57(3):355-360

25. Hipps D, Ausania F, Manas DM, Rose JD, French JJ (2013) Selective Interarterial Radiation Therapy (SIRT) in Colorectal Liver Metastases: How Do We Monitor Response? HPB Surg. 2013:570808

26. Shady W, Sotirchos VS, Do RK et al (2016) Surrogate Imaging Biomarkers of Response of Colorectal Liver Metastases After Salvage Radioembolization Using 90Y-Loaded Resin Microspheres. AJR Am J Roentgenol. 207(3):661-670

27. Reiner CS, Gordic S, Puippe G et al (2016) Histogram Analysis of CT Perfusion of Hepatocellular Carcinoma for Predicting Response to Transarterial Radioembolization: Value of Tumor Heterogeneity Assessment. Cardiovasc Intervent Radiol. 39(3):400-408

28. Schmeel FC, Simon B, Sabet A et al (2017) Diffusion-weighted magnetic resonance imaging predicts survival in patients with liver-predominant metastatic colorectal cancer shortly after selective internal radiation therapy. Eur Radiol. 27(3):966-975

29. Barabasch A, Kraemer NA, Ciritsis A et al (2015) Diagnostic accuracy of diffusion-weighted magnetic resonance imaging versus positron emission tomography/computed tomography for early response assessment of liver metastases to Y90-radioembolization. Invest Radiol. 50(6):409-415

30. Paris F, Fuks Z, Kang A et al (2001) Endothelial apoptosis as the primary lesion initiating intestinal radiation damage in mice. Science. 293(5528):293-297

31. Wong CY, Salem R, Raman S, Gates VL, Dworkin HJ (2002) Evaluating 90Yglass microsphere treatment response of unresectable colorectal liver metastases by [18F]FDG PET: a comparison with CT or MRI. Eur J Nucl Med Mol Imaging. 29(6):815-820

32. Singh P, Anil G (2014) Yttrium-90 radioembolization of liver tumors: what do the images tell us? Cancer Imaging. 13(4):645-657

33. Nakazawa T, Kokubu S, Shibuya A et al (2007) Radiofrequency ablation of hepatocellular carcinoma: correlation between local tumor progression after ablation and ablative margin. AJR Am J Roentgenol. 188(2):480-488

34. Llovet JM, Di Bisceglie AM, Bruix J et al (2008) Design and endpoints of clinical trials in hepatocellular carcinoma. J Natl Cancer Inst. 100(10):698-711

35. Lencioni R, Llovet JM (2010) Modified RECIST (mRECIST) assessment for hepatocellular carcinoma. Semin Liver Dis. 30(1):52-60

36. Chung WS, Lee KH, Park MS et al (2012) Enhancement patterns of hepatocellular carcinoma after transarterial chemoembolization using drugeluting beads on arterial phase CT images: a pilot retrospective study. AJR Am J Roentgenol. 199(2):349-359

37. European Association For The Study Of The Liver; European Organisation For Research And Treatment Of Cancer (2012) EASL-EORTC clinical practice guidelines: management of hepatocellular carcinoma. J Hepatol. 56(4):908-943

38. Takayasu K, Arii S, Matsuo N et al (2000) Comparison of CT findings with resected specimens after chemoembolization with iodized oil for hepatocellular carcinoma. AJR Am J Roentgenol. 175(3):699-704

39. Galizia MS, Tore HG, Chalian H, Yaghmai V (2011) Evaluation of hepatocellular carcinoma size using two-dimensional and volumetric analysis: effect on liver transplantation eligibility. Acad Radiol. 18(12):1555-1560

40. Yaghmai V, Miller FH, Rezai P, Benson AB 3rd, Salem R (2011) Response to treatment series: part 2, tumor response assessment--using new and conventional criteria. AJR Am J Roentgenol. 197(1):18-27

41. Chalian H, Tochetto SM, Tore HG, Rezai P, Yaghmai V (2012) Hepatic tumors: region-of-interest versus volumetric analysis for quantification of attenuation at CT. Radiology. 262(3):853-861

42. Kim S, Mannelli L, Hajdu CH et al (2010) Hepatocellular carcinoma: assessment of response to transarterial chemoembolization with image subtraction. J Magn Reson Imaging. 31(2):348-355 
43. Khan MA, Combs CS, Brunt EM et al (2000) Positron emission tomography scanning in the evaluation of hepatocellular carcinoma. J Hepatol. 32(5): 792-797

44. Kamel IR, Bluemke DA, Eng J et al (2006) The role of functional MR imaging in the assessment of tumor response after chemoembolization in patients with hepatocellular carcinoma. J Vasc Interv Radiol. 17(3):505-512

45. Kloeckner R, Otto G, Biesterfeld S, Oberholzer K, Dueber C, Pitton MB (2010) MDCT versus MRI assessment of tumor response after transarterial chemoembolization for the treatment of hepatocellular carcinoma. Cardiovasc Intervent Radiol. 33(3):532-540

46. Boas FE, Do B, Louie JD et al (2015) Optimal imaging surveillance schedules after liver-directed therapy for hepatocellular carcinoma. J Vasc Interv Radiol. 26(1):69-73

47. Goshima S, Kanematsu M, Kondo H et al (2008) Evaluating local hepatocellular carcinoma recurrence post-transcatheter arterial chemoembolization: is diffusion-weighted MRI reliable as an indicator? J Magn Reson Imaging. 27(4):834-839

48. Yuan Z, Ye XD, Dong $S$ et al (2010) Role of magnetic resonance diffusionweighted imaging in evaluating response after chemoembolization of hepatocellular carcinoma. Eur J Radiol. 75(1):e9-14.

49. Taouli B, Johnson RS, Hajdu CH et al (2013) Hepatocellular carcinoma: perfusion quantification with dynamic contrast-enhanced MRI. AJR Am J Roentgenol. 201(4):795-800

50. Sabet A, Ahmadzadehfar H, Bruhman J et al (2014) Survival in patients with hepatocellular carcinoma treated with $90 \mathrm{Y}$-microsphere radioembolization. Prediction by 18F-FDG PET. Nuklearmedizin. 53(2):39-45

51. Kim HJ, Kim TK, Kim PN et al (2006) Assessment of the therapeutic response of hepatocellular carcinoma treated with transcatheter arterial chemoembolization: comparison of contrast-enhanced sonography and 3phase computed tomography. J Ultrasound Med. 25(4):477-486

52. Moschouris H, Malagari K, Papadaki MG, Kornezos I, Matsaidonis D (2010) Contrast-enhanced ultrasonography of hepatocellular carcinoma after chemoembolisation using drug-eluting beads: a pilot study focused on sustained tumor necrosis. Cardiovasc Intervent Radiol. 33(5): 1022-1027

53. Finelli A, Ismaila N, Russo P (2017) Management of Small Renal Masses: American Society of Clinical Oncology Clinical Practice Guideline Summary. J Oncol Pract. 13(4):276-278

54. Aron M, Gill IS (2005) Renal tumor ablation. Curr Opin Urol. 15(5):298-305

55. Onik GM, Reyes G, Cohen JK, Porterfield B (1993) Ultrasound characteristics of renal cryosurgery. Urology. 42(2):212-215

56. Ho VB, Allen SF, Hood MN, Choyke PL (2002) Renal masses: quantitative assessment of enhancement with dynamic MR imaging. Radiology. 224(3): 695-700

57. Zagoria RJ, Traver MA, Werle DM, Perini M, Hayasaka S, Clark PE (2007) Oncologic efficacy of CT-guided percutaneous radiofrequency ablation of renal cell carcinomas. AJR Am J Roentgenol. 189(2):429-436

58. Krokidis ME, Orsi F, Katsanos K, Helmberger T, Adam A (2017) CIRSE Guidelines on Percutaneous Ablation of Small Renal Cell Carcinoma. Cardiovasc Intervent Radiol. 40(2):177-191

59. Russo U, Maestroni U, Papapietro RV et al. (2018) Imaging after radiofrequency ablation of renal tumors. Future Oncol 14(28):2915-2922.

60. Atwell TD, Carter RE, Schmit GD et al (2012) Complications following 573 percutaneous renal radiofrequency and cryoablation procedures. J Vasc Interv Radiol. 23(1):48-54

61. Gervais DA, Arellano RS, McGovern FJ, McDougal WS, Mueller PR (2005) Radiofrequency ablation of renal cell carcinoma: part 2, Lessons learned with ablation of 100 tumors. AJR Am J Roentgenol. 185(1):72-80

62. Hiraoka K, Kawauchi A, Nakamura T, Soh J, Mikami K, Miki T (2009) Radiofrequency ablation for renal tumors: our experience. Int J Urol. 16(11): 869-873

63. Takaki H, Soga N, Kanda H et al (2014) Radiofrequency ablation versus radical nephrectomy: clinical outcomes for stage $\mathrm{T} 1 \mathrm{~b}$ renal cell carcinoma. Radiology. 270(1):292-299

64. Atwell TD, Schmit GD, Boorjian SA et al (2013) Percutaneous ablation of renal masses measuring $3.0 \mathrm{~cm}$ and smaller: comparative local control and complications after radiofrequency ablation and cryoablation. AJR Am J Roentgenol. 200(2):461-466

65. Gervais DA, McGovern FJ, Wood BJ, Goldberg SN, McDougal WS, Mueller PR (2000) Radio-frequency ablation of renal cell carcinoma: early clinical experience. Radiology. 217(3):665-672
66. Caviezel A, Terraz S, Schmidlin F, Becker C, Iselin CE (2008) Percutaneous cryoablation of small kidney tumors under magnetic resonance imaging guidance: medium-term follow-up. Scand J Urol Nephrol. 42(5):412-416

67. Davenport MS, Caoili EM, Cohan RH et al (2009) MRI and CT characteristics of successfully ablated renal masses: Imaging surveillance after radiofrequency ablation. AJR Am J Roentgenol. 192(6):1571-1578

68. Schirmang TC, Mayo-Smith WW, Dupuy DE, Beland MD, Grand DJ (2009) Kidney neoplasms: renal halo sign after percutaneous radiofrequency ablation--incidence and clinical importance in 101 consecutive patients. Radiology. 253(1):263-269

69. Durack JC, Richioud B, Lyon J, Solomon SB (2014) Late emergence of contrast-enhancing fat necrosis mimicking tumor seeding after renal cryoablation. J Vasc Interv Radiol. 25(1):133-137

70. Yang Q, Qi H, Zhang R et al (2017) Risk Factors for Local Progression after Percutaneous Radiofrequency Ablation of Lung Tumors: Evaluation Based on a Review of 147 Tumors. J Vasc Interv Radiol. 28(4):481-489

71. Belfiore G, Moggio G, Tedeschi E et al (2004) CT-guided radiofrequency ablation: a potential complementary therapy for patients with unresectable primary lung cancer--a preliminary report of 33 patients. AJR Am J Roentgenol. 183(4):1003-1011

72. Palussiere J, Lagarde P, Auperin A, Deschamps F, Chomy F, de Baere T (2015) Percutaneous lung thermal ablation of non-surgical clinical N0 nonsmall cell lung cancer: results of eight years' experience in 87 patients from two centers. Cardiovasc Intervent Radiol. 38(1):160-166

73. Palussiere J, Marcet B, Descat E et al (2011) Lung tumors treated with percutaneous radiofrequency ablation: computed tomography imaging follow-up. Cardiovasc Intervent Radiol. 34(5):989-997

74. Fanucchi O, Ambrogi MC, Aprile $V$ et al (2016) Long-term results of percutaneous radiofrequency ablation of pulmonary metastases: a single institution experience. Interact Cardiovasc Thorac Surg. 23(1): 57-64

75. McDevitt JL, Mouli SK, Nemcek AA, Lewandowski RJ, Salem R, Sato KT (2016) Percutaneous Cryoablation for the Treatment of Primary and Metastatic Lung Tumors: Identification of Risk Factors for Recurrence and Major Complications. J Vasc Interv Radiol. 27(9):1371-1379

76. Wang Y, Li G, Li W, He X, Xu L (2015) Radiofrequency ablation of advanced lung tumors: imaging features, local control, and follow-up protocol. Int J Clin Exp Med. 8(10):18137-18143

77. de Baere T, Auperin A, Deschamps F et al (2015) Radiofrequency ablation is a valid treatment option for lung metastases: experience in 566 patients with 1037 metastases. Ann Oncol. 26(5):987-991

78. Yamauchi Y, Izumi Y, Hashimoto K et al (2012) Percutaneous cryoablation for the treatment of medically inoperable stage I non-small cell lung cancer. PLoS One. 7(3):e33223

79. Ambrogi MC, Fanucchi $O$, Cioni $R$ et al (2011) Long-term results of radiofrequency ablation treatment of stage I non-small cell lung cancer: a prospective intention-to-treat study. J Thorac Oncol. 6(12): 2044-2051

80. Ito N, Nakatsuka S, Inoue M et al (2012) Computed tomographic appearance of lung tumors treated with percutaneous cryoablation. J Vasc Interv Radiol. 23(8):1043-1052

81. Chaudhry A, Grechushkin V, Hoshmand M et al (2015) Characteristic CT Findings After Percutaneous Cryoablation Treatment of Malignant Lung Nodules. Medicine (Baltimore). 94(42):e1672

82. Chou HP, Chen CK, Shen SH et al (2015) Percutaneous cryoablation for inoperable malignant lung tumors: midterm results. Cryobiology. 70(1): 60-65

83. Yang $X, Y e X$, Zheng A et al (2014) Percutaneous microwave ablation of stage I medically inoperable non-small cell lung cancer: clinical evaluation of 47 cases. J Surg Oncol. 110(6):758-763

84. Zhong L, Sun S, Shi J et al (2017) Clinical analysis on 113 patients with lung cancer treated by percutaneous CT-guided microwave ablation. J Thorac Dis. 9(3):590-597

85. Iguchi T, Hiraki T, Gobara H et al (2015) Percutaneous radiofrequency ablation of lung cancer presenting as ground-glass opacity. Cardiovasc Intervent Radiol. 38(2):409-415

86. Nour-Eldin NE, Naguib NN, Tawfik AM, Gruber-Rouh T, Zangos S, Vogl TJ (2014) $C T$ volumetric assessment of pulmonary neoplasms after radiofrequency ablation: when to consider a second intervention? J Vasc Interv Radiol. 25(3):347-354 
87. Cheng M, Fay M, Steinke K (2016) Percutaneous CT-guided thermal ablation as salvage therapy for recurrent non-small cell lung cancer after external beam radiotherapy: A retrospective study. Int J Hyperthermia. 32(3):316-323

88. Han X, Yang X, Ye X J et al (2015) Computed tomography-guided percutaneous microwave ablation of patients 75 years of age and older with early-stage nonsmall cell lung cancer. Indian J Cancer. 52(Suppl 2): e56-e60

89. Sharma A, Digumarthy SR, Kalra MK, Lanuti M, Shepard JA (2010) Reversible locoregional lymph node enlargement after radiofrequency ablation of lung tumors. AJR Am J Roentgenol. 194(5):1250-1256

90. Izaaryene J, Vidal V, Bartoli JM, Loundou A, Gaubert JY (2017) Role of dualenergy computed tomography in detecting early recurrences of lung tumors treated with radiofrequency ablation. Int J Hyperthermia. 33(6):653-658

91. Parvizi N, Chung D, Little MW, Gleeson FV, Anderson EM (2016) Does perfusion $C T$ play a role in the evaluation of percutaneous microwaveablated lung tumors? Clin Radiol. 71(11):1137-1142

92. Alafate A, Shinya T, Okumura Y et al (2013) The Maximum standardized uptake value is more reliable than size measurement in early follow-up to evaluate potential pulmonary malignancies following radiofrequency ablation. Acta Med Okayama. 67(2):105-112

93. Higaki F, Okumura Y, Sato $S$ et al (2008) Preliminary retrospective investigation of FDG-PET/CT timing in follow-up of ablated lung tumor. Ann Nucl Med. 22(3):157-163

94. LoGiurato B, Matthews R, Safaie E et al (2015) 18F-FDG PET-CT: predicting recurrence in patients following percutaneous cryoablation treatment for stage I primary non-small-cell lung cancer. Nucl Med Commun. 36(9):908-913

95. Singnurkar A, Solomon SB, Gonen M, Larson SM, Schoder H (2010) 18F-FDG $\mathrm{PET} / \mathrm{CT}$ for the prediction and detection of local recurrence after radiofrequency ablation of malignant lung lesions. J Nucl Med. 51(12):1833-1840

96. Suzawa N, Yamakado K, Takao M, Taguchi O, Yamada T, Takeda K (2013) Detection of local tumor progression by (18)F-FDG PET/CT following lung radiofrequency ablation: PET versus CT. Clin Nucl Med. 38(4):e166-e170

97. Bonichon F, Palussiere J, Godbert $Y$ et al (2013) Diagnostic accuracy of 18FFDG PET/CT for assessing response to radiofrequency ablation treatment in lung metastases: a multicenter prospective study. Eur J Nucl Med Mol Imaging. 40(12):1817-1827

98. Sharma A, Lanuti M, He W, Palmer EL, Shepard JA, Digumarthy SR (2013) Increase in fluorodeoxyglucose positron emission tomography activity following complete radiofrequency ablation of lung tumors. J Comput Assist Tomogr. 37(1):9-14

99. Chen J, Lin ZY, Wu ZB, Chen ZW, Chen YP (2017) Magnetic resonance imaging evaluation after radiofrequency ablation for malignant lung tumors. J Cancer Res Ther. 13(4):669-675

100. Roman A, Kaltenbach B, Gruber-Rouh T, Naguib NN, Vogl TJ, Nour-Eldin NA (2018) The role of MRI in the early evaluation of lung microwave ablation. Int J Hyperthermia. 34(6):883-890

101. Okuma T, Matsuoka T, Yamamoto A, Hamamoto S, Nakamura K, Inoue $Y$ (2009) Assessment of early treatment response after CT-guided radiofrequency ablation of unresectable lung tumors by diffusion-weighted MRI: a pilot study. Br J Radiol. 82(984):989-994

102. Staal F, Taghavi M, Imani F et al (2019) CT texture analyses of colorectal liver metastases before and after thermal ablation can predict local tumor progression. Insights Imaging 10(Suppl 2):20

103. Maas M, Rutten IJ, Nelemans PJ et al (2011) What is the most accurate whole-body imaging modality for assessment of local and distant recurrent disease in colorectal cancer? A meta-analysis : imaging for recurrent colorectal cancer. Eur J Nucl Med Mol Imaging. 38(8):1560-1571

104. Gavanier M, Ayav A, Sellal C et al (2016) CT imaging findings in patients with advanced hepatocellular carcinoma treated with sorafenib: Alternative response criteria (Choi, European Association for the Study of the Liver, and modified Response Evaluation Criteria in Solid Tumor (mRECIST)) versus RECIST 1.1. Eur J Radiol. 85(1):103-112

105. Ronot M, Bouattour M, Wassermann J et al (2014) Alternative Response Criteria (Choi, European association for the study of the liver, and modified Response Evaluation Criteria in Solid Tumors [RECIST]) Versus RECIST 1.1 in patients with advanced hepatocellular carcinoma treated with sorafenib. Oncologist. 19(4):394-402

106. Weng Z, Ertle J, Zheng S et al (2013) Choi criteria are superior in evaluating tumor response in patients treated with transarterial radioembolization for hepatocellular carcinoma. Oncol Lett. 6(6):1707-1712
107. Chaudhry M, McGinty K, Mervak B et al (2020) The LI-RADS Version 2018 MRI Treatment Response Algorithm: Evaluation of Ablated Hepatocellular Carcinoma. Radiology. 294(2):320-326

\section{Publisher's Note}

Springer Nature remains neutral with regard to jurisdictional claims in published maps and institutional affiliations.

\section{Submit your manuscript to a SpringerOpen ${ }^{\circ}$ journal and benefit from:}

- Convenient online submission

- Rigorous peer review

- Open access: articles freely available online

- High visibility within the field

- Retaining the copyright to your article

Submit your next manuscript at $\boldsymbol{\nabla}$ springeropen.com 